\title{
Corpo e cidade: sensibilidades, memórias e histórias
}

Fabiana Aparecida Olívia ${ }^{1}$

fabianaaolivia@gmail.com

Guimarães, Maria de Fátima. Corpo e cidade: sensibilidades, memórias e história. Jundiaí: Paco Editorial, 2013.

Corpo e cidade: sensibilidades, memórias e histórias, livro de Maria de Fátima Guimarães, foi publicado em 2013, pela editora Paco Editorial, e aborda o cotidiano urbano da cidade de Bragança, interior de São Paulo, em fins do século XIX e nas duas primeiras décadas do século $X X$.

Maria de Fátima Guimarães é doutora em educação, mestre em ciências da informação e especialista em arquivos. É professora da Universidade São Francisco (UFS), em Itatiba - São Paulo, onde atua na graduação, no Programa de Pós-Graduação em Educação e coordena a gestão de acervo do Centro de Documentação e Apoio à Pesquisa em História da Educação Cdaph. Dedica-se à pesquisa sobre a história da educação brasileira, especialmente no que se refere à educação do corpo.

$\mathrm{Na}$ obra, a autora entrecruza memórias e histórias locais, atentando para visões de civilização, privacidade e individualismo. Através de fotografias, periódicos, processos, crimes, bem como suas próprias memórias e de seus contemporâneos, Maria de Fátima, proporciona ao leitor uma compreensão do relevante processo de modernização da cidade paulista de Bragança, que é sua cidade natal.

Guimarães tem um olhar sensível aos sujeitos históricos focalizados, apresentando-os como seres integrais, portadores de sensibilidades, racionalidades, corporeidade. Percebe que, àquela época, muitas vezes as imagens dos corpos eram silenciadas, apagadas, homogeneizadas em práticas discursivas contemporâneas.

Composto de quatro capítulos, o trabalho destaca aspectos relacionados a sensibilidades do corpo humano, no que se refere ao cotidiano da cidade do

\footnotetext{
${ }^{1}$ Mestranda em educação pela Universidade Federal de São João del-Rei (UFSJ).
} 
interior de São Paulo, então conhecida por Bragança, no final do século XIX e início do século $\mathrm{XX}$. A obra tem sua origem na própria trajetória de vida, experiências e lembranças da autora, "muitas dessas marcas estavam ancoradas em inquietações e sensações inscritas em minha memória e em desejos latentes de minha vontade que, por sua vez, trazem nuanças do meu tempo" (p.15). Para a realização do trabalho, fundamenta-se no campo de análise da história da educação brasileira, privilegiadamente no que tange à educação do corpo. Nesse sentido, baseia-se nas memórias e histórias locais, apoiando-se em bibliografia ampla e atualizada.

$\mathrm{Na}$ introdução, situa a cidade de Bragança, seu clima e suas particularidades. A autora expõe algumas de suas memórias e inquietações da época de criança. Sobre as fotografias, as pinturas e os bustos que observava espalhados pela cidade, a autora revela: "tinha a sensação infantil de que elas estavam em vigília permanente a espreitar as almas e os sonhos dos moradores da cidade" (p.19). Guimarães considera que "essas representações, estáticas e silenciosas, também têm suas raízes e força nas narrativas e memórias de moradores da cidade" (p. 19).

A autora discorre sobre o corpo que, na modernidade, "torna-se objeto do conhecimento científico de diferentes instituições sociais, produtoras de discursos e práticas especializadas, que se revestem da pressuposta competência daqueles que os enunciam (Chauí, 2006; Foucault, 1987)" (p.21). Discursos e práticas que, segundo ela, acabam gerando, em algumas situações, ações e comportamentos que tendem a legitimar a violência, a discriminação, a segregação e a exclusão de amplos segmentos sociais. Dessa forma, tem como hipótese que esse corpo, em diferentes situações, ao mesmo tempo violou a condição de vítima e de objeto do conhecimento científico, bem como reagiu, resistiu e negou esse controle e aprisionamento dos seus desejos e pulsões, que deram significados às experiências vivenciadas por eles em determinada época.

Com relação ao limite temporal da obra, a autora leva em conta que o período foi marcado pelo aumento populacional e a rápida urbanização do país, que tiveram relação direta com a modernidade, já que propiciaram crescimento 
das cidades, a industrialização e a formação do trabalho assalariado. Tal período também "foi marcado pela imagem da multidão nas grandes cidades e pelas epidemias que legitimavam a implementação de políticas sanitárias destinadas a garantir o controle das doenças e dos corpos" (p.23). Nesse contexto, tornava-se urgente a necessidade de higienizar e controlar os corpos.

De acordo com Abreu Jr., Guimarães e Carvalho (2009), o higienismo surge na Europa em meados do século XIX, com a preocupação de produzir meios para sanear a sociedade, através da difusão do saber médico e jurídico. Essas ideias se manifestaram no Brasil, em fins do século XIX e início do XX. Com o higienismo, "procuram-se usar os meios (tecnologias positivas de poder) que vão divulgar esse saber para efetivamente realizar a ação corretiva da educação na sociedade" (p.6).

Nesse viés, a escola tem um papel fundamental para a efetivação desses ideais. De acordo com Guimarães,

a escola tornou-se um dos emblemas do avanço, do progresso e da civilização, já que ela seria o espaço de práticas e de convívio sociais destinados às iniciativas moralizantes e higiênicas, mediante a escolarização e o letramento crescentes da população. (p.33)

Nesse contexto, surge a história de Bragança, em que a autora buscou compreender algumas sensibilidades referentes ao corpo no imaginário local, explorando vestígios em diversas bases documentais, vislumbrando, assim, o entrecruzamento de visões modernas com algumas sensibilidades relativas ao corpo.

No primeiro capítulo do livro, "À guisa de um intermezzo: o corpo na trama da justiça", a autora faz uma análise de um conjunto de quatro fotografias de um exame de corpo de delito, reunidos a um processo civil de separação no ano de 1918, no qual o sujeito fotografado é descrito como um "enucoide", no dizer do médico legista. Guimarães discorre sobre a violência refinada e sorrateira praticada pela justiça, através das fotografias daquele indivíduo. "O retratado, além de ser responsabilizado por ter enganado sua esposa, deveria expiar a culpa de causar 'grande horror e nojo' devido a seu 'deffeito physico irremediável', o qual the teria determinado o desvio de conduta" (p.41). E ainda, "essas fotografias foram produzidas para diferenciar, 
esmiuçar e classificar o corpo retratado, seu 'deffeito physico' e seu comportamento desviante - seu corpo estigmatizado" (p.42). Dessa forma, a autora analisa o conjunto de fotografias desse processo de anulação do casamento como objeto passível de normatização e classificação. Guimarães recorre a Foucault, quanto ao poder disciplinador e ao controle dos corpos que, muitas vezes, se estabelece na sociedade.

Já no segundo capítulo, "O cenário", a autora versa sobre o contexto histórico, tanto mundial quanto nacional, sobre relações capitalistas e a busca da modernidade. Nas primeiras décadas do século XX, no Brasil, o desejo era "conduzir o país à modernidade, em contraposição ao atraso e à miséria que se reconheciam no território nacional, diante do panorama mundial" (p.62). Guimarães afirma que, no período, uma das alternativas para evitar que o país caminhasse para a barbárie, seria privilegiar a educação, a saúde e a formação para o trabalho como condição primordial para o progresso e desenvolvimento da nação. Para isso, precisava-se do apoio de intelectuais, políticos, médicos e de outros sujeitos de influência na sociedade. Naquele momento, foram diversas as tentativas de controlar e de governar o cidadão, planejadas pelo Estado e por diferentes instituições. O corpo do homem, tanto urbano quanto rural, deveria ser disciplinarizado. A higiene, a postura, os gestos, o grau de escolaridade, a saúde, dentre outros, eram focos de controle. Ainda nesse capítulo, a autora situa a cidade de Bragança e suas especificidades, tomando como suporte periódicos e fotografias da época.

O capítulo três, "A cidade plural: em busca de outras vozes", refere-se à elevação da então freguesia de Bragança à cidade, bem como as características de sua população e alguns acontecimentos significantes ocorridos naquela cidade. Para tanto, a autora recorreu a documentos, artigos e notícias de jornais. Guimarães percebe que "as histórias e as memórias dos tropeiros e dos pobres tenderam a ser silenciadas nos almanaques e anuários privilegiados, assim como a história e a memória dos negros" (p.98).

Segundo a autora, sobre as tentativas de controle do espaço e do corpo, na época estudada, os hospitais e sanatórios eram meios de isolamento daqueles indivíduos considerados prejudiciais para a população e para a 
cidade, já que as doenças e o perigo das epidemias assustavam os contemporâneos do período. Ressalta que as duas primeiras décadas do século $X X$ formam um período em que o saneamento da cidade era a grande preocupação das autoridades. Ainda no terceiro capítulo, Guimarães trata sobre a educação no período, principalmente no que se refere às iniciativas em prol da instrução pública, e analisa algumas fotos de grupos escolares da cidade.

"O corpo: entre a materialidade das fotografias e as práticas de leitura", quarto e último capítulo do livro, refere-se às sensibilidades relativas ao corpo. Para a autora,

muitas dessas sensibilidades acabaram por endossar algumas iniciativas do poder público, destinadas à produção do corpo saudável e escolarizado, em um contexto social no qual o trabalho passou a ser dignificado como uma das virtudes humanas. (p.137)

A partir daí, a autora expõe o que era o corpo modelo da época, aquele civilizado, disciplinado, capaz de respeitar as leis e viver bem em sociedade. $\mathrm{E}$ também apresenta ao leitor o contraponto desse corpo modelo, "era o corpo daquele que não se moldou nem se mostrou dócil à racionalidade instrumental" (p.138), o desempregado, o mendigo, a prostituta, o vadio, o alcoólatra, o doente, enfim, todo aquele que desestabilizava o status quo e colocava em dúvida a ordem social necessária à produção capitalista.

No decorrer do capítulo, Guimarães situa as práticas de philantropia que ocorriam na época e tinham como intuito excluir aquele corpo indesejado da sociedade. Analisa também alguns periódicos locais e fotografias da época. Percebe que as fotografias pertencentes às elites tendem a existir em maior número, porém, em alguns casos, as classes trabalhadoras também foram retratadas, "fotografias que denotavam a clara diferença entre o cotidiano do trabalho e o cotidiano das elites locais" (p.149).

Ao final da obra, relata que, nas histórias e memórias da cidade de Bragança, deparou-se com sensibilidades plurais relativas ao corpo, "corpo, por vezes, violentado pela miséria ou atormentado pelo preconceito ou pelo desejo de atender às convenções e padrões sociais" (p.183). A autora destaca que a concepção de corpo valorizada e privilegiada nos periódicos, era a do corpo 
saudável, escolarizado e formado para o trabalho. Dessa forma, os periódicos se apresentaram como dispositivos que difundiam ideias e preceitos. Sobre os processos judiciais e as fotografias analisadas, Guimarães conclui que, além da imagem de corpo escolarizado e saudável, "valorizava-se a imagem do corpo do branco em detrimento do corpo do negro ou mestiço, do homem em detrimento do corpo feminino e, sobretudo, do corpo das elites locais em detrimento do das classes trabalhadoras" (p.184).

$O$ livro resenhado traz grande riqueza de detalhes, com fotos, processos crime e periódicos analisados. Demonstrando sua posição sobre a importância do estudo do corpo e suas sensibilidades, Guimarães apresenta, durante sua obra análises cuidadosas de fotografias, periódicos, processos, crimes, bem como suas próprias rememorações e de seus contemporâneos, evidenciando um cuidado com os indícios. O olhar que a autora lança sobre seu objeto de pesquisa traz grande contribuição para os estudos histórico-educacionais. A clareza nos objetivos e a delimitação precisa das questões proporcionam uma leitura rica e oferecem a oportunidade de pensar, questionar e enriquecer futuros estudos na temática. Ao mesmo tempo, as análises empreendidas são de grande valia aos interessados na área da história da educação brasileira, principalmente no trato com o corpo.

\section{Referência bibliográfica}

ABREU JR., Laerthe de Moraes; GUIMARÃES, Paula Cristina David; CARVALHO, Eliane Vianey de. Por uma análise foucaultiana do poder e da ordem dos discursos sobre o higienismo na educação brasileira (1925-1930). In: CONGRESSO DE PESQUISA E ENSINO EM HISTÓRIA DA EDUCAÇÃO EM MINAS GERAIS: (Re)Visitando as Minas e desvelando os Gerais, V, 2009, Montes Claros, MG. Anais... Montes Claros: Unimontes, 2009. 1 CD-ROM. 